\title{
Primary Care Patients Who Prefer Emergency Department Instead of Family Physician; How Do They Use Their Family Physician?
}

\author{
DD Hatice Tuba Akbayram
}

Department of Family Medicine, Gaziantep University Faculty of Medicine, Gaziantep, Turkey

\begin{abstract}
Aim: Patients with non-urgent (NU) issues go to the emergency department (ED) rather than to primary care providers, and this has become a worldwide problem. Thus, this study aimed to determine the characteristics of NU patients and to compare the use of EDs and family physicians (FPs).

Materials and Methods: This cross-sectional study was conducted in the ED of a tertiary hospital. A questionnaire was administered to NU (level 5) patients (aged $\geq 18$ years) defined using the five-level triage system.

Results: Upper respiratory tract infection symptoms (19.6\%) and gastrointestinal system problems (18.6\%) were the most common complaints. FP contact was made before the ED visit by $13.3 \%$ of the patients. Most of them (79.6\%) stated that they were satisfied with their FP and $6.1 \%$ never went to the FP. As regards health problems, 39.5\% and $29.3 \%$ reported that they preferred the FP and ED, respectively. The visiting frequency of $\geq 3$ times per year was $30.1 \%$ for the ED and was $42.9 \%$ for the FPs. The frequency of ED visits of those who were not satisfied with their FP was significantly higher than those of other participants $(p=0.025)$. A significant relationship was found between the frequency of ED visits and FP visits.
\end{abstract}

Conclusion: Less than half of the patients preferred FPs when they had health problems. Those who visited the ED also frequently visited FPs. Dissatisfaction with the FP is associated with the frequency of visits in the ED.

Keywords: Emergency department, non-urgent use, family physician, primary care

\section{Introduction}

Using primary healthcare system effectively results in increased patient satisfaction, improved health status of patients, reduced use of hospital resources and reduced health costs (1). Despite the expansion of primary healthcare services around the world, the first choice of many people in the healthcare system remains the emergency departments (EDs) (2). It has been reported that the rate of non-urgent $(\mathrm{NU})$ patient visits to EDs varies between $12 \%$ and $56 \%$ in different countries (3).

EDs are designed to provide continuous, rapid, qualified and accessible healthcare for injuries and acute diseases that require urgent intervention (4). However, NU use of EDs is common in many countries and is an important factor in overcrowding (5). The increasing number of patients leads to problems such as increased waiting time of patients, insufficient health care, and increased morbidity and mortality rates (6). NU visits may lead to problems like unnecessary examinations, wrong treatments, excessive health expenditures and the loss of comprehensive care services that can be provided by primary care physicians (7).

It is difficult to evaluate and define patient visits that are NU or inappropriate for EDs. It is generally defined as visits that do not increase the probability of a negative risk in health conditions with a delay of a few hours (8). These patients are generally 
primary care patients and can be given appropriate care by the general practitioner or family physician (FP) without the need for fast and special services of the ED (9).

The perceived severity of the disease, the desire for a quick recovery, the efficiency of primary health care services, and the lack of access to primary care and other alternative health services are important factors in NU patients visiting EDs (10-12).

Although there is no clear data on the number of NU visit rate in Turkey, it is known that the number of ED visits increase gradually. ED visits per capita were 1.11 in 2009 and increased to 1.12 in 2013 (13). It was reported that approximately 290 million people applied to hospitals affiliated to the Ministry of Health between January and October 2017, and 28.5\% of them were ED admissions (14).

Primary healthcare services are provided by FPs in Turkey since last 10 years. Each person has a registered FP. When a person is not satisfied, he/she has right to choose different FP. FPs generally serve within office hours (8.00 am to $17.00 \mathrm{pm}$ ). Patients can apply EDs or hospitals directly instead of their FP during office hours. In Turkey, there are a limited number of studies researching the reasons of NU patients preferring EDs instead of FP. This study was conducted to determine the characteristics of $\mathrm{NU}$ patients who applied to the ED of a university hospital located in the southern Turkey, their reasons for admission and to compare the features of use FPs.

\section{Materials and Methods}

This cross-sectional study was conducted between April 2019 and June 2019 during office hours (between 9:00 a.m. and 5:00 p.m. on weekdays). It was carried out in the ED of Gaziantep University Faculty of Medicine, Training and Research Hospital. Gaziantep is one of the largest cities in southern Turkey with a population of 2.7 million. The hospital's ED is the largest ED in the region by serving approximately 255,000 patients per year. The hospital is located in a central area where patients can easily arrive from all regions of the city.

According to the triage operation procedure of the ED, in which the study was conducted about, patients are evaluated by the nurses and doctors in charge of triage in accordance with the 5-level triage system by the priority of injury. The patients are classified as follows: Severely injured patients are classified with code red (level 1-2), middle injured patients are classified with code yellow (level 3-4), patients with good general condition, stable vital signs and health problems that do not require urgent intervention are classified as NU (triage level-5) with code green.

Inclusion criteria in the study were being 18 years of age or older, being Turkish speaker and classification with triage level 5 . The patients with this feature were informed about the study by the triage doctors. Questionnaires were handed out to the patients who agreed to participate in the study. Patients completed the questionnaires after the consultation at the ED. The patients who gave incomplete answers to the questions in the patient survey, cases for examinations that cannot be performed under family healthcare center's conditions (such as radiography, ultrasonography), forensic cases and mentally disabled patients were excluded from the study.

The questionnaire, which was prepared by scanning the literature (15-17), contained 15 questions divided into two sections. In the first part of the patient survey, the sociodemographic characteristics of the patients (age, gender, education level, income status, marital status, place of residence) were questioned. In the second part of the questionnaire, there were nine questions about the patients' use of EDs and FPs.

\section{Ethics}

Ethical approval was obtained from the Ethics Committee of Gaziantep University Medical Faculty (decision number: 2019/103, date: 06.03.2019). Informed consent was obtained from the patients who participated in the study.

\section{Statistical Analysis}

SPSS (Statistical Package of Social Sciences) version 23.0 software was used for statistical analysis and $p<0.05$ was considered statistically significant. Number and percentage values were used for descriptive statistics, and categorical variables were evaluated by the chi-square test.

\section{Results}

We enrolled 402 patients during the study period. Ten people were excluded due to missing data. Thus, a total of 392 people were included in the study. The average age of the patients was $40.3 \pm 13.8$ (minimum: 18 - maximum: 81 ) years, and $47.2 \%$ in the $30-50$ age range. $50.8 \%(n=199)$ of the participants were male, 33.4\% $(n=131)$ were high school graduates, $50.5 \%(n=198)$ were middle level incomed and $76.3 \%(n=299)$ were married. The socio-demographic characteristics of the patients are shown in Table 1.

It was found out that $19.6 \%(n=77)$ of the complaints at $E D$ admissions had problems related to the upper respiratory system, 18.6\% ( $n=73$ ) had complaints about the gastrointestinal system, 13.3\% ( $n=52)$ had musculo-skeletal system (Table 2$)$.

It was found that $13.3 \%(n=52)$ of the patients who applied to FP before applying to the ED. The majority of the participants (79.6\% $n=312)$ stated that they were satisfied with the FP, 10.5\% $(n=41)$ 
did not know their FP. Six percent of the participants stated that they never went to the family doctor. Twenty-four (6.1\%) patients stated that they never went to the family physician. In case of any health problem, the $39.5 \%(n=155)$ chose FPs and 29.3\% $(n=115)$ chose EDs as their first prefer. The most common reason for applying to the FP was for prescribing medication with the rate of $59.8 \%(n=220)$ and after that, for being examined for health problems with the rate of $40.2 \%(n=148)$. The decision between the ED and FP of the patients are shown in Table 3.

42.9\% $(n=168)$ of the patients stated that they visited their FP and $30.1 \%(n=118)$ visited the ED three or more times in a year. A significant correlation was found between the frequency of ED visits and the frequency of FP visits. It was found that more than half (55.9\%) of those who visited the ED three or more in a year also visited the FP three or more in a year (Table 4).

The frequency of ED visits was found to be significantly higher $(p=0.025)$ of those who were not satisfied with their FP compared to other participants (those who did not know the FP and were satisfied with the FP) $(p=0.025)$. In the Table 5 the comparison of the participants' dissatisfaction with their FP and the visit frequency of ED were shown in.

\section{Discussion}

The first contact point between general practitioner and FP is providing personalized healthcare and this is important for directing individuals with serious injuries or diseases to

\begin{tabular}{|l|l|l|l|}
\hline \multicolumn{2}{|l|}{ Table 1. Demographic characteristics of the patients } & n & $\%$ \\
\hline \multirow{3}{*}{ Gender } & Male & 199 & 50.8 \\
\cline { 2 - 4 } & Female & 193 & 49.2 \\
\hline \multirow{4}{*}{ Age category } & Under 30 & 108 & 27.6 \\
\cline { 2 - 4 } & $30-50$ years & 185 & 47.2 \\
\cline { 2 - 4 } & Over 50 years old & 99 & 25.3 \\
\hline \multirow{3}{*}{ Marital status } & Married & 299 & 76.3 \\
\cline { 2 - 4 } & Not married & 93 & 23.7 \\
\hline \multirow{3}{*}{ Educational level } & Low & 54 & 13.8 \\
\cline { 2 - 4 } & Medium & 198 & 50.5 \\
\cline { 2 - 4 } & Good & 140 & 35.7 \\
\hline & Primary school & 99 & 25.3 \\
\cline { 2 - 4 } & Secondary school & 102 & 26.0 \\
\cline { 2 - 4 } & High school & 131 & 33.4 \\
\cline { 2 - 4 } & University & 60 & 15.3 \\
\hline Place of residence & Province & 328 & 83.7 \\
\cline { 2 - 4 } & County/village & 64 & 16.3 \\
\hline
\end{tabular}

Table 2. Complaints of patients while emergency service applications

\begin{tabular}{|l|l|l|}
\hline & $\mathbf{n}$ & $\%$ \\
\hline Complaints about the upper respiratory tract & 77 & 19.6 \\
\hline Complaints about the gastrointestinal system & 73 & 18.6 \\
\hline Muscle-joint complaints & 52 & 13.3 \\
\hline Complaints about genital and urinary tract & 48 & 12.2 \\
\hline Dizziness, headache, and confusion & 48 & 12.2 \\
\hline Minor traumas (fall-hit) & 43 & 11.0 \\
\hline Skin related complaints & 25 & 6.4 \\
\hline Psychological issues & 11 & 2.8 \\
\hline Other & 15 & 3.8 \\
\hline Total & 392 & 100.0 \\
\hline
\end{tabular}




\begin{tabular}{|c|c|c|c|}
\hline & & $\mathbf{n}$ & $\%$ \\
\hline Primary healthcare centers before the emergency service & Yes & 52 & 13.3 \\
\hline \multirow{2}{*}{ Visited primary healthcare center } & Yes & 368 & 93.9 \\
\hline & No & 24 & 6.1 \\
\hline \multirow[t]{2}{*}{ Satisfaction with the family physician } & Satisfied & 312 & 79.6 \\
\hline & Unsatisfied & 39 & 9.9 \\
\hline The most preferred application institutions for health problems & Family physician & 155 & 39.5 \\
\hline \multirow{3}{*}{ Visit frequency of family physician } & One or less in a year & 49 & 12.5 \\
\hline & 1 or 2 times a year & 175 & 44.6 \\
\hline & 3 and more in a year & 168 & 42.9 \\
\hline \multirow{3}{*}{ Visit frequency of emergency department } & 1-2 times in my life & 69 & 17.6 \\
\hline & 1 or 2 times a year & 205 & 52.3 \\
\hline & 3 and more in a year & 118 & 30.1 \\
\hline The most common reasons for using family physician* & Being examined for health problems & 148 & 40.2 \\
\hline
\end{tabular}

\begin{tabular}{|c|c|c|c|c|c|c|}
\hline \multicolumn{7}{|c|}{ Frequency of family physician use } \\
\hline & & & $\begin{array}{l}\text { Less than } 1 \text { in a } \\
\text { year }\end{array}$ & $\begin{array}{l}1-2 \text { times per } \\
\text { year }\end{array}$ & $\begin{array}{l}3 \text { and more in a } \\
\text { year }\end{array}$ & $\begin{array}{l}p \text {-value } \\
x^{2} \text { test }\end{array}$ \\
\hline \multirow{5}{*}{$\begin{array}{l}\text { Frequency of } \\
\text { emergency } \\
\text { department use }\end{array}$} & \multirow[t]{2}{*}{ Less than 1 in a year } & $n$ & 17 & 40 & 12 & \multirow{5}{*}{0.001} \\
\hline & & $\%$ & 24.6 & 58 & 17.4 & \\
\hline & Once or twice a year & $\%$ & 9.8 & 46.3 & 43.9 & \\
\hline & \multirow[t]{2}{*}{3 and more in a year } & $n$ & 12 & 40 & 66 & \\
\hline & & $\%$ & 10.2 & 33.9 & 55.9 & \\
\hline
\end{tabular}

appropriate healthcare services (18). In a study conducted with patients with low level emergency in Canada, it was reported that approximately half of the patients sought alternative care before applying to the ED, and the rate of those who applied to the FP was $25.9 \%$ (19). A study done by Unwin et al. (20) reported that approximately $40 \%$ of the participants contacted a healthcare provider before applying to the ED. In a study conducted in Italy, it was reported that $84.1 \%$ of the participants applied to the ED at their own request or on the advice of their relatives without being referred by a physician (21). Akpinar et al. (16) from Turkey, 
Table 5. Comparison of dissatisfaction with the family physician and the frequency of emergency department use

\begin{tabular}{|c|c|c|c|c|c|}
\hline & & & $\begin{array}{l}\text { Not satisfied with the } \\
\text { family physician }\end{array}$ & $\begin{array}{l}\text { Does not know the } \\
\text { family physician or is } \\
\text { satisfied }\end{array}$ & $\begin{array}{l}p \text {-value } \\
x^{2} \text { test }\end{array}$ \\
\hline \multirow{4}{*}{$\begin{array}{l}\text { Frequency of } \\
\text { emergency } \\
\text { department } \\
\text { use }\end{array}$} & \multirow[t]{2}{*}{ Less than 1 in a year } & $\mathrm{n}$ & 4 & 65 & \multirow{4}{*}{0.025} \\
\hline & & $\%$ & 10.3 & 18.4 & \\
\hline & Once or twice a year & $\mathrm{n}$ & 16 & 189 & \\
\hline & 3 and more in a year & $\%$ & 48.7 & 28.0 & \\
\hline
\end{tabular}

the rate of those who applied to another physician before applying to the ED was reported with the rate of $12.2 \%$. In our study, it was found that only $13.3 \%$ of the patients went to their FP before applying to the ED. These findings show that a large proportion of patients in Turkey, where there is no obligatory referral system, use the ED as the first place of application.

In this study, it was found that complaints about the upper respiratory system, gastrointestinal and musculo-skeletal system were the leading complaints of ED admissions. Similarly, in other studies, complaints related to the upper respiratory tract, gastrointestinal system and conditions that cause pain were reported to be common $(11,12,16,17,22)$.

The results of our study revealed that most of the NU patients who applied to the ED prefer hospitals and EDs more for their health problems. In the other studies, it has been shown that a significant portion of NU patients consider the ED as the place where they want their health problems to be solved $(19,20)$. In a study conducted in England, it was reported that $29 \%$ of the patients who applied to the ED for NU situations thought that general practitioners could not help (23). In the study conducted by Idil et al. (17), it was stated that approximately one third of the patients (28.7\%) did not prefer their FP when they had health problems.

In a study conducted in the United States, it was reported that patients' communication satisfaction with primary healthcare providers was not associated with NU ED choices. However, in the same study, it was found that patients with poor to moderate quality perceptions for primary healthcare were more likely to choose EDs (24). Akpinar et al. (16), reported that NU patients had an average of $68.1 \%$ satisfaction rate with their FPs and that there was no correlation between dissatisfaction and frequent use of the ED. Similarly, in this study, it was found that most of the patients were satisfied with their FPs. However, differently, in this study, a significant relationship was found between dissatisfaction with the FP and the frequency of ED visits ( $p=0.025)$.
It has been reported in the literature that people who prefer EDs frequently also prefer primary healthcare services and health services extensively (25-27). Similarly, in this study, it was shown that those who prefer the ED frequently also prefer primary healthcare centers frequently. Oh et al. (28) reported that those who had a history of frequent ED visits within one year had higher rates of inappropriate emergency use the following year. In a recent study conducted in Saudi Arabia, it was reported that approximately one third (32.5\%) of NU patients visited the ED three or more times in the last year (15). Idil et al. (17) reported that $17.1 \%$ of the patients visited the ED with similar complaints in the previous two weeks. Similar to other studies, this study found that approximately one third of the participants visited the ED or more times in a year.

\section{Study Limitations}

The limitation of our study is that the study was conducted in a single center within a limited time. The results of the study cannot be generalized. The data in the study are based on the statements of the participants. In the study, the survey form was kept short in order not to interfere with the functioning of the $E D$, and the detailed reasons why the patients preferred ED and/ or FP were not questioned. Therefore, investigating the reasons why prefer ED and FP in future studies will provide a better enlightenment on the subject.

\section{Conclusion}

As a result, it has been found that approximately two-thirds of NU patients do not prefer FPs when they have health problems. It has been found that users who frequently use the ED also frequently use FP. Dissatisfaction with the FP is associated with the frequent visits of the EDs. More studies should be conducted to increase the satisfaction of the patients with their FPs and to make them prefer FPs more. 


\section{Ethics}

Ethics Committee Approval: Ethical approval was obtained from the Ethics Committee of Gaziantep University Medical Faculty (decision number: 2019/103, date: 06.03.2019).

Informed Consent: Informed consent was obtained from the patients who participated in the study.

Peer-review: Externally peer-reviewed.

Financial Disclosure: The author declared that this study received no financial support.

\section{References}

1. Tiagi $R$, Chechulin $Y$. The effect of rostering with a patient enrolment model on emergency department utilization. Healthc Policy. 2014;9:105-21.

2. Pacheco J, Cuadrado C, Martínez-Gutiérrez MS. Urgent care centres reduce emergency department and primary care same-day visits: a natural experiment. Health Policy Plan. 2019;34:170-7.

3. Seeger I, Kreienmeyer L, Hoffmann F, Freitag MH. Cross-sectional study in an out-of-hours primary care centre in northwestern Germany - patient characteristics and the urgency of their treatment. BMC Fam Pract. 2019;20:41.

4. Khangura JK, Flodgren G, Perera R, Rowe BH, Shepperd S. Primary care professionals providing non-urgent care in hospital emergency departments. Cochrane Database Syst Rev. 2012;11:CD002097.

5. Pines JM, Hilton JA, Weber EJ, Alkemade AJ, Al Shabanah H, Anderson PD, et al. International perspectives on emergency department crowding. Acad Emerg Med. 2011;18:1358-70.

6. Di Somma S, Paladino L, Vaughan L, Lalle I, Magrini L, Magnanti M. Overcrowding in emergency department: an international issue. Intern Emerg Med. 2015;10:171-5.

7. Huang LC, Chung WF, Liu SW, Wu JC, Chen LF, Chen YC. Characteristics of Non-Emergent Visits in Emergency Departments: Profiles and Longitudinal Pattern Changes in Taiwan, 2000-2010. Int J Environ Res Public Health. 2019;16:1999

8. Uscher-Pines L, Pines J, Kellermann A, Gillen E, Mehrotra A. Emergency department visits for nonurgent conditions: systematic literature review. Am J Manag Care. 2013;19:47-59.

9. Bezzina AJ, Smith PB, Cromwell D, Eagar K. Primary care patients in the emergency department: who are they? A review of the definition of the 'primary care patient' in the emergency department. Emerg Med Australas. 2005;17:472-9.

10. Oslislo S, Heintze C, Schmiedhofer M, Möckel M, Schenk L, Holzinger F. How to decide adequately? Qualitative study of GPs' view on decision-making in self-referred and physician-referred emergency department consultations in Berlin, Germany. BMJ Open. 2019;9:e026786.

11. Miyazawa A, Maeno T, Shaku F, Tsutsumi M, Kurihara H, Takayashiki A, et al. Inappropriate use of the emergency department for nonurgent conditions: Patient characteristics and associated factors at a Japanese hospital. J Gen Fam Med. 2019;20:146-53.

12. Şimşek P, Gürsoy A. Turkish health care providers' views on inappropriate use of emergency department: Who, when and why? Int Emerg Nurs. 2016;27:31-6
13. Bektemur G, Osmanbeyoglu N, Cander B. Eurasian Journal of Emergency services report. Eurasian J Emerg Med. 2015;14:1-8.

14. 2017 Yılı Ocak-Ekim Dönemi Acil Servislere iliş̧kin Veriler: Türkiye Kamu Hastaneleri Genel Müdürlüğü ìstatistik, Analiz, Raporlama ve Stratejik Yönetim Dairesi Başkanlığı verileri Aralık 2017 Available at: https:// dosyamerkez.saglik.gov.tr/Eklenti/23496,2017-ocak-ekim-donemi-acilservisverileri2pdf.pdf?0 (Accessed on: 13.12.2019).

15. Al-Otmy SS, Abduljabbar AZ, Al-Raddadi RM, Farahat F. Factors associated with non-urgent visits to the emergency department in a tertiary care centre, western Saudi Arabia: cross-sectional study. BMJ Open. 2020;10:e035951.

16. Akpinar Y, Demirci H, Budak E, Baran AK, Candar A, Ocakoglu G. Why do patients with minor complaints choose emergency departments and does satisfaction with primary care services influence their decisions? Prim Health Care Res Dev. 2018;19:398-406.

17. Idil H, Kilic TY, Toker I, Dura Turan K, Yesilaras M. Non-urgent adult patients in the emergency department: Causes and patient characteristics. Turk J Emerg Med. 2018;18:71-4.

18. Brekke M, Carelli F, Zarbailov N, Javashvili G, Wilm S, Timonen M, et al. Undergraduate medical education in general practice/family medicine throughout Europe - a descriptive study. BMC Med Educ. 2013;13:157.

19. Sancton K, Sloss L, Berkowitz J, Strydom N, McCracken R. Low-acuity presentations to the emergency department: Reasons for and access to other health care providers before presentation. Can Fam Physician. 2018;64:e35460

20. Unwin M, Kinsman L, Rigby S. Why are we waiting? Patients' perspectives for accessing emergency department services with non-urgent complaints. Int Emerg Nurs. 2016;29:3-8.

21. Bianco A, Pileggi C, Angelillo IF. Non-urgent visits to a hospital emergency department in Italy. Public Health. 2003;117:250-5.

22. Backman AS, Blomqvist P, Lagerlund M, Carlsson-Holm E, Adami J. Characteristics of non-urgent patients. Cross-sectional study of emergency department and primary care patients. Scand J Prim Health Care. 2008;26:181-7.

23. Atenstaedt R, Gregory J, Price-Jones C, Newman J, Roberts L, Turner J. Why do patients with nonurgent conditions present to the Emergency Department despite the availability of alternative services? Eur J Emerg Med. 2015;22:3703.

24. Xin H. Patient Dissatisfaction With Primary Care and Nonurgent Emergency Department Use. J Ambul Care Manage. 2019;42:284-94.

25. Byrne M, Murphy AW, Plunkett PK, McGee HM, Murray A, Bury G. Frequent attenders to an emergency department: a study of primary health care use, medical profile, and psychosocial characteristics. Ann Emerg Med. 2003;41:309-18.

26. Hansagi H, Olsson M, Sjöberg S, Tomson Y, Göransson S. Frequent use of the hospital emergency department is indicative of high use of other health care services. Ann Emerg Med. 2001;37:561-7.

27. Cunningham A, Mautner D, Ku B, Scott K, LaNoue M. Frequent emergency department visitors are frequent primary care visitors and report unmet primary care needs. J Eval Clin Pract. 2017;23:567-73.

28. Oh HC, Chow WL, Gao Y, Tiah L, Goh SH, Mohan T. Factors associated with inappropriate attendances at the emergency department of a tertiary hospital in Singapore. Singapore Med J. 2020;61:5-80. 